\title{
Nitrogênio e época de colheita nos componentes da produtividade de forragem e sementes de capim-mombaça
}

\author{
Armindo Barth Neto(1), Vinicíus Scandolara Boleta ${ }^{(1)}$, Edson José Pancera Júnior ${ }^{(1)}$, \\ Gleice Menezes de Almeida( ${ }^{(1)}$, Marcos Weber do Canto(1), Eliane Gasparino(1) e Leonardo Fiorio Baltazar ${ }^{(1)}$ \\ (1)Universidade Estadual de Maringá (UEM), Avenida Colombo, no 5790, CEP 87020-900 Maringá, PR. E-mail: arm_barth@hotmail.com, \\ vsbagro@hotmail.com, edsaljunior@hotmail.com, gleice_m.a@hotmail.com, mwcanto@uem.br, egasparino@uem.br, dub_leo@hotmail.com
}

\begin{abstract}
Resumo - O objetivo deste trabalho foi avaliar o efeito de doses de nitrogênio e de épocas de colheita de sementes sobre componentes de produtividade de forragem e sementes de capim-mombaça (Panicum maximum cultivar Mombaça). Os tratamentos foram constituídos das doses 0, 75, 150, 225 e $300 \mathrm{~kg} \mathrm{ha}^{-1}$ de $\mathrm{N}$ e da colheita das sementes aos 8 e 14 dias após a antese. Utilizou-se o delineamento em blocos ao acaso em parcelas subdivididas, com quatro repetições. A produtividade de forragem e de lâmina foliar foi afetada positiva e linearmente pelas doses de N. Os caracteres densidade de perfilhos com panículas, número de sementes aparentes e de sementes puras por panícula, e produtividade de sementes aparentes e puras foram afetados pela interação entre doses de $\mathrm{N}$ e época de colheita. Observou-se correlação positiva do número de sementes por panícula e do peso de mil sementes com as produtividades de sementes aparentes e puras. As maiores produtividades de sementes aparentes e puras - 89,1 e $28,2 \mathrm{~kg} \mathrm{ha}^{-1}$, respectivamente - foram obtidas com as doses de 241,2 e $250,0 \mathrm{~kg} \mathrm{ha}^{-1}$ de N, aos oito dias após a antese.
\end{abstract}

Termos para indexação: Panicum maximum, florescimento, gramínea tropical, sementes de forrageiras.

\section{Nitrogen and harvesting time on the components of forage and seed yield of guineagrass cultivar 'Mombaça'}

\begin{abstract}
The objective of this work was to evaluate the effects of nitrogen doses and harvesting time, on the yield components of forage and seed production of Mombaça Guineagrass (Panicum maximum cultivar Mombaça). The treatments were composed by $\mathrm{N}$ doses $\left(0,75,150,225\right.$ and $\left.300 \mathrm{~kg} \mathrm{ha}^{-1}\right)$ and two harvesting times ( 8 and 14 days after anthesis). The experimental design was the randomized complete block in a split-plot arrangement with four replicates. Forage and leaf lamina yield were positively and linearly affected by $\mathrm{N}$ doses. The characters density of fertile tillers, apparent number of seeds and number of pure seeds per panicle, and apparent and pure seed yields were significantly affected by the interaction between $\mathrm{N}$ doses and harvesting time. Positive correlation was observed between apparent or pure seed yield and number of seed per panicle and weight of one thousand seeds. The highest apparent seed yield of $89.1 \mathrm{~kg} \mathrm{ha}^{-1}$ and pure seed yield of $28.2 \mathrm{~kg} \mathrm{ha}^{-1}$ were observed on nitrogen doses at 241.2 and $250.0 \mathrm{~kg} \mathrm{ha}^{-1}$, respectively, at 8 days after anthesis.
\end{abstract}

Index terms: Panicum maximum, flowering, tropical grass, forage seeds.

\section{Introdução}

O Brasil é o maior produtor mundial de sementes de forrageiras tropicais, porém possui baixa produtividade.

No Brasil, pastos de Panicum maximum Jacq. são cultivados em vastas áreas, e as cultivares mais utilizadas são as de porte alto e elevada capacidade produtiva de forragem (Jank et al., 2010). A demanda por sementes de P. maximum tem sidocrescente, mas a qualidade da semente produzida é baixa (Dias \& Alves, 2008), e fracassos na formação de pastos ocorrem com frequência.

Pastagens de P. maximum normalmente apresentam alta resposta ao nitrogênio, nutriente que tem influência marcante sobre a fisiologia do pasto e sobre o potencial produtivo de forragem e sementes (Muir \& Jank, 2004; Euclides et al., 2007; Braga et al., 2009; Canto et al., 2009).

Sabe-se que a deficiência de $\mathrm{N}$ é um dos fatores mais limitantes à produção de sementes de gramíneas tropicais (Boonman, 1993). Contudo, resultados de estudos com $P$. maximum sobre produção de sementes são controversos. Monteiro et al. (1984) avaliaram doses de $\mathrm{N}$ entre 0 e $145 \mathrm{~kg} \mathrm{ha}^{-1}$ em pastos de capim-colonião (Panicum maximum cultivar Colonião) e não verificaram diferença na produtividade de sementes. Outros estudos, no entanto, constataram que a adubação com $\mathrm{N}$ aumentou 
a produtividade de sementes (Condé \& Garcia, 1988; Sangakkara, 1988; Joaquin et al., 2001). A maioria dos estudos, entre os quais se destacam os de Gobius et al. (2001), Jornada et al. (2005) e Kumar et al. (2005), evidencia que, em gramíneas tropicais, o incremento na produção de sementes em resposta à adubação de $\mathrm{N}$ está relacionado ao aumento de inflorescências, com taxas ótimas de N entre 100 e $180 \mathrm{~kg} \mathrm{ha}^{-1}$. Sangakkara (1988) verificou que o $\mathrm{N}$ aumenta a produtividade de sementes de $P$. maximum por causa de seus efeitos sobre a densidade de perfilhos com panículas e sobre o número de espiguetas por panícula.

Zago et al. (1984) relataram alterações expressivas na produtividade de sementes de capim-colonião em consequência da época de colheita.

No caso de pastos de capim-mombaça, não se encontram trabalhos em que adubações com $\mathrm{N}$ e épocas de colheita de sementes tenham sido testados simultaneamente. Além disso, aspectos relacionados ao florescimento e aos componentes da produtividade de sementes não têm sido enfatizados pelas pesquisas.

O objetivo deste trabalho foi avaliar os efeitos de doses de $\mathrm{N}$ e de épocas de colheita de sementes em capim-mombaça, sobre os componentes de produtividade de forragem e de sementes.

\section{Material e Métodos}

O experimento foi desenvolvido no Campus Avançado da Universidade Estadual de Maringá (UEM), localizado em Umuarama, região ao noroeste do Paraná, localizada a $23^{\circ} 44^{\prime} \mathrm{S}, 53^{\circ} 17^{\prime} \mathrm{W}$ e altitude de $480 \mathrm{~m}$. O solo da área é um Argissolo Vermelho Amarelo distrófico típico (Santos et al., 2006) de textura muito arenosa (superior a 70\%), e o clima é do tipo Cfa, conforme a classificação de Köppen.
A região se caracteriza por temperaturas médias anuais que variam de 18 a $22^{\circ} \mathrm{C}$ e a pluviometria registra índices entre 1.000 a $1.500 \mathrm{~mm}$ anuais (Nery et al., 2002). Valores médios de temperatura do ar, umidade relativa do ar (UR), insolação e precipitação pluviométrica total (PP) no período experimental, que ocorreu de dezembro de 2007 a abril de 2008, encontram-se na Tabela 1. A distribuição de chuvas no período de amostragem foi regular.

O somatório de graus-dia (GD) foi calculado pela equação proposta por Villa Nova et al., 2007, tendo-se adotado a temperatura base $15^{\circ} \mathrm{C}$ : GD $=($ temperatura diária máxima + temperatura diária mínima)/2 - 15 .

O preparo do solo para o estabelecimento do pasto foi realizado em 6/9/2006. A adubação de plantio utilizada foi de $180 \mathrm{~kg} \mathrm{ha}^{-1}$ de $\mathrm{P}_{2} \mathrm{O}_{5}$ (superfosfato simples) e $60 \mathrm{~kg} \mathrm{ha}^{-1}$ de $\mathrm{K}_{2} \mathrm{O}$ (cloreto de potássio), aplicada a lanço e incorporada ao solo. A semeadura foi realizada a lanço, com $8 \mathrm{~kg} \mathrm{ha}^{-1}$ de sementes viáveis, incorporadas a aproximadamente $1,5 \mathrm{~cm}$ com grade niveladora. As subparcelas experimentais foram demarcadas, roçadas e adubadas com $80 \mathrm{~kg} \mathrm{ha}^{-1}$ de $\mathrm{N}$ (ureia), em janeiro de 2007. Uma nova adubação com $\mathrm{P}_{2} \mathrm{O}_{5}$ (superfosfato simples, $180 \mathrm{~kg} \mathrm{ha}^{-1}$ ) e $\mathrm{K}_{2} \mathrm{O}$ (cloreto de potássio, $60 \mathrm{~kg} \mathrm{ha}^{-1}$ ) foi realizada em cobertura, em novembro de 2007 , conforme a Sociedade Brasileira de Ciência do Solo (1995).

O solo coletado na camada de $0-20 \mathrm{~cm}$, em setembro de 2007, apresentou: $\mathrm{pH}-\mathrm{H}_{2} \mathrm{O}, 5,5 ; \mathrm{Al}^{3+}, 0,2 \mathrm{cmol}_{\mathrm{c}} \mathrm{dm}^{-3}$; $\mathrm{H}+\mathrm{Al}^{3+}, 3,54 \mathrm{cmol}_{\mathrm{c}} \mathrm{dm}^{-3} ; \mathrm{Ca}^{2+}+\mathrm{Mg}^{2+}, 2,01 \mathrm{cmol}_{\mathrm{c}} \mathrm{dm}^{-3}$; $\mathrm{K}^{+}, 0,17 \mathrm{cmol}_{\mathrm{c}} \mathrm{dm}^{-3} ; \mathrm{P}, 8,2 \mathrm{mg} \mathrm{dm}^{-3} ; \mathrm{C}, 13,45 \mathrm{~g} \mathrm{dm}^{-3}$; soma de bases, $2,18 \mathrm{cmol}_{\mathrm{c}} \mathrm{dm}^{-3}$; capacidade de troca cationica, $5,72 \mathrm{cmol}_{c} \mathrm{dm}^{-3}$; saturação por bases, $38 \%$.

$\mathrm{O}$ período experimental iniciou-se com o corte de uniformização da forragem em 20/10/2007 até a segunda colheita de sementes em junho de 2008 .

Tabela 1. Valores médios de temperatura do ar, precipitação pluviométrica total (PP), umidade relativa do ar (UR) e insolação no período experimental.

\begin{tabular}{|c|c|c|c|c|c|c|}
\hline \multirow[t]{2}{*}{ Mês/ano } & \multicolumn{3}{|c|}{ Temperatura $\left({ }^{\circ} \mathrm{C}\right)$} & \multirow{2}{*}{$\begin{array}{c}\text { PP } \\
(\mathrm{mm})\end{array}$} & \multirow{2}{*}{$\begin{array}{l}\text { UR } \\
(\%) \\
\end{array}$} & \multirow{2}{*}{$\begin{array}{l}\text { Insolação } \\
\left(\mathrm{h} \operatorname{dia}^{-1}\right)\end{array}$} \\
\hline & Máxima & Mínima & Média & & & \\
\hline Novembro/2007 & 30,9 & 20,3 & 25,6 & 236,6 & 49,9 & 7,8 \\
\hline Dezembro/2007 & 31,9 & 19,7 & 25,8 & 142,1 & 60,8 & 7,4 \\
\hline Janeiro/2008 & 30,9 & 19,8 & 25,3 & 91,7 & 62,2 & 6,2 \\
\hline Fevereiro/2008 & 32,0 & 19,4 & 25,7 & 223,8 & 59,9 & 7,3 \\
\hline Março/2008 & 30,7 & 18,2 & 24,5 & 49,8 & 59,0 & 8,2 \\
\hline Abril/2008 & 31,7 & 17,4 & 24,6 & 100,5 & 70,6 & 6,7 \\
\hline Maio/2008 & 26,4 & 15,0 & 20,7 & 98,3 & 75,9 & 6,7 \\
\hline
\end{tabular}


Os tratamentos foram constituídos pelas doses 0 , $75,150,225$ e $300 \mathrm{~kg} \mathrm{ha}^{-1}$ de $\mathrm{N}$, e pelas épocas de colheita de sementes, realizadas aos $8(26 / 5 / 2008)$ e $14(1 / 6 / 2008)$ dias após a antese. O experimento foi realizado em blocos ao acaso com parcelas subdivididas, com quatro repetições. As doses de $\mathrm{N}$ foram aplicadas na parcela $\left(36 \mathrm{~m}^{2}\right)$, e a época de colheita de sementes constituiu a subparcela $\left(18 \mathrm{~m}^{2}\right)$. A fonte de $\mathrm{N}$ utilizada para os tratamentos foi a ureia, aplicada em cobertura e de forma fracionada em duas aplicações iguais, em 3/12/2007 e 15/1/2008. A ocorrência da antese foi estimada quando cerca de $30 \%$ de perfilhos escolhidos ao acaso apresentavam espiguetas com anteras exteriorizadas.

A produtividade de forragem foi avaliada no centro da subparcela. As plantas foram cortadas com tesoura de poda a $30 \mathrm{~cm}$ de altura do solo, usando-se moldura de ferro com $1 \mathrm{~m}^{2}$ de área, sempre que a altura do pasto atingia $90 \mathrm{~cm}$. O manejo de cortes da forragem baseouse na altura do pasto, de acordo com recomendações propostas por Carnevalli et al. (2006). As amostras foram armazenadas em freezer a $-15^{\circ} \mathrm{C}$, posteriormente separadas em lâmina foliar, material morto e colmo e, em seguida, secadas em estufa de ar forçado por 56 horas a $60^{\circ} \mathrm{C}$, para a avaliação da matéria seca (MS).

A forragem restante foi cortada a $30 \mathrm{~cm}$ de altura do solo com roçadeira costal. Esse material foi removido da área experimental de modo a favorecer a rebrotação de folhas e o crescimento de perfilhos. Na ausência de adubação nitrogenada, somente um corte foi realizado, em 22/1/2008, por causa do baixo crescimento do pasto. Nas doses de 75 e $150 \mathrm{~kg} \mathrm{ha}^{-1}$ de $\mathrm{N}$, os cortes da forragem foram realizados em 13/12/2007 e $10 / 1 / 2008$ e, nas doses de 225 e $300 \mathrm{~kg} \mathrm{ha}^{-1}$ de $\mathrm{N}$, os cortes foram realizados em 9/12/2007, 6/1 e 22/1/2008 e em 7/12/2007, 4/1 e 20/1/2008, respectivamente. Após o corte da forragem, em 15/2/2008, os pastos de capim-colonião foram diferidos, conforme a época indicada por Monteiro et al. (1984), para a produção de sementes. A forragem do corte em 15/2/2008, para o diferimento, foi acrescentada também aos cortes prévios. Nesse último corte, em todas as subparcelas adubadas com $\mathrm{N}$, a altura do pasto, em média, foi superior a $1 \mathrm{~m}$.

A emergência de panícula, o início de florescimento e a antese foram avaliados em duas observações por semana, a partir de um mês após o corte da forragem (15/3/2008). As fenofases emergência de panícula e início de florescimento foram estabelecidas quando o pasto atingiu cinco panículas em emergência por $\mathrm{m}^{2} \mathrm{e}$ entre cinco e dez panículas totalmente exteriorizadas por $\mathrm{m}^{2}$, respectivamente (Boonman, 1971). Por ocasião da colheita de sementes, a massa de forragem foi avaliada, coletando-se amostras cortadas próximo do solo, em duas áreas escolhidas como representativas da média do pasto em cada subparcela. A massa de forragem na colheita de sementes não foi considerada no cálculo da produtividade de forragem. O número de perfilhos vegetativos e com panículas foi contado na porção central da subparcela, em duas áreas, tendo-se usado moldura de ferro de $0,25 \mathrm{~m}^{2}$. A seguir, foram colhidos dez perfilhos vegetativos e dez perfilhos com panículas por subparcela, para avaliação da massa por perfilho, representativos do tamanho de perfilhos nos respectivos estádios. O número de sementes por panícula foi avaliado pela coleta aleatória, na porção central da subparcela, de dez panículas cortadas imediatamente acima da folha bandeira. As sementes foram secadas à sombra.

Para avaliação da pureza física de sementes, foram separadas manualmente sementes com cariopse de sementes vazias. O peso de mil sementes e a análise de germinação de sementes foram realizados no Laboratório de Sementes da UEM. O teste de germinação de sementes foi feito em dezembro de 2008, sete meses após a colheita, tendo-se usado caixas gerbox e papel-filtro umedecido, à temperatura de 20$30^{\circ} \mathrm{C}$ (Brasil, 1992). As sementes foram tratadas com ácido sulfúrico concentrado durante cinco minutos, conforme a metodologia descrita por Zago et al. (1984).

A produtividade de sementes aparentes foi obtida pela multiplicação da densidade de perfilhos com panícula, número de sementes aparentes por panícula e peso de mil sementes. Para o cálculo das produtividades de sementes puras e puras viáveis, substituiu-se, nessa equação, respectivamente, o número de sementes aparentes pelas puras, e multiplicou-se pela percentagem de germinação de sementes. Os índices de colheita de sementes aparentes e puras foram obtidos, pela divisão dos respectivos valores de produtividade de sementes aparentes e puras pela massa de forragem. $\mathrm{O}$ valor cultural foi obtido pelo produto das percentagens de sementes puras e de germinação de sementes dividido por 100 . 
Os dados foram submetidos à análise da variância. As médias, nas épocas de colheita de sementes, foram comparadas pelo teste de Tukey a 5\% de probabilidade, e as respostas das variáveis às doses de $\mathrm{N}$ foram submetidas à análise de regressão (SAS Institute, 2002). Coeficientes de correlação de Pearson foram calculados por meio das médias dos tratamentos, para determinar as relações dos componentes de produtividade de sementes com as produtividades de sementes aparentes, puras e puras viáveis.

\section{Resultados e Discussão}

As produtividades de colmo, lâmina foliar, material morto e forragem foram influenciadas pela dose de $\mathrm{N}$ (Figura 1 A, B, C e D). O modelo linear foi o que melhor se ajustou à relação entre as doses de $\mathrm{N}$ e essas produtividades.

A frequência de cortes da forragem foi de dois cortes, nas doses 75 e $150 \mathrm{~kg} \mathrm{ha}^{-1}$ de $\mathrm{N}$, e de três cortes, nas doses de 225 e $300 \mathrm{~kg} \mathrm{ha}^{-1}$ de N. No período avaliado, a produtividade de colmo e de material morto foi baixa e a de lâmina foliar, alta. Isso pode ser atribuído às altas doses de $\mathrm{N}$ e também ao manejo de cortes da forragem,
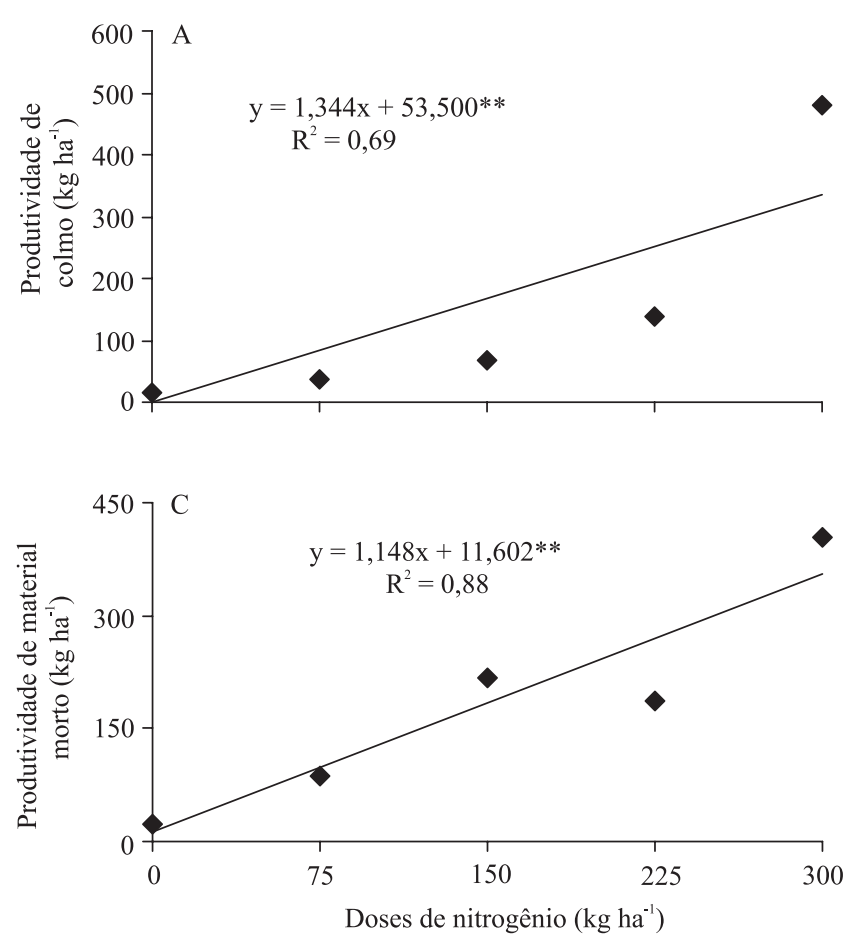

Figura 1. Produtividade de colmo, lâmina foliar, material morto e de forragem, em pastos de capim-mombaça em função de doses de nitrogênio. que determinou área foliar remanescente mínima nos perfilhos para iniciar a rebrotação de folhas, em detrimento de colmos e material morto (Carnevalli et al., 2006).

$\mathrm{O}$ aumento nos componentes de produtividade em resposta à elevação na taxa de $\mathrm{N}$ era esperado em P. maximum (Muir \& Jank, 2004; Canto et al.; 2009), e confirma a importância da adubação nitrogenada para a produção de forragem com alta proporção de lâmina foliar.

No que se refere à massa de forragem e de perfilhos vegetativos, e à densidade de perfilhos vegetativos e totais, a interação entre dose de $\mathrm{N}$ e época de colheita não foi significativa. A massa de forragem e de perfilho vegetativo ajustou-se linearmente ao efeito das doses de $\mathrm{N}$ (Figura $2 \mathrm{~A}$ e $\mathrm{B}$ ). Houve efeito quadrático da dose de $\mathrm{N}$ sobre a densidade de perfilhos e de perfilhos vegetativos, com os maiores valores - $392 \mathrm{e}$ 363 perfilhos $\mathrm{m}^{-2}$ - observados nas doses de 267,6 e $265,0 \mathrm{~kg} \mathrm{ha}^{-1} \mathrm{de} \mathrm{N}$, respectivamente (Figura $2 \mathrm{C}$ e D).

A elevação na massa de forragem com o aumento da dose de $\mathrm{N}$ deveu-se, sobretudo, ao aumento na densidade de perfilhos vegetativos. De acordo com

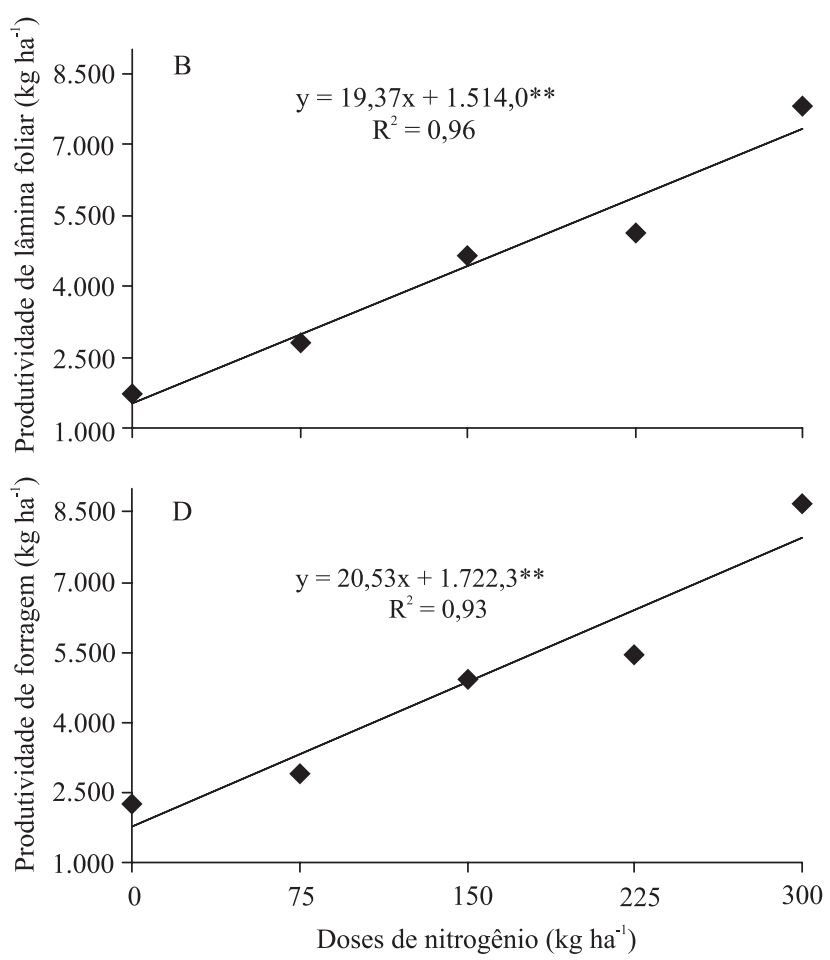


Joaquin et al. (2001), as adubações com $\mathrm{N}$ influenciam o crescimento vegetativo em gramíneas tropicais que se encontram diferidas para a produção de sementes, e resultam em altas massas de forragem na colheita. A densidade de perfilhos vegetativos e a densidade total de perfilhos foi superior à obtida por Monteiro et al. (1984), com o capim-colonião e doses de $\mathrm{N}$ entre 0 e $145 \mathrm{~kg} \mathrm{ha}^{-1}$, e por Joaquim et al. (2001), com o capim-tanzânia (Panicum maximum cultivar Tanzânia) e doses de $\mathrm{N}$ entre 0 e $150 \mathrm{~kg} \mathrm{ha}^{-1}$.

$\mathrm{Na}$ ausência de adubação nitrogenada, a emergência de panícula ocorreu de 26/4 a 10/5/2008 e o início de florescimento de 7/5 a 17/5/2008. Nos pastos adubados com $\mathrm{N}$, a emergência de panícula ocorreu de 23/4 a 14/5/2008 e o início de florescimento, de 2/5 a 10/5/2008. A data da antese não diferiu e, na média, foi estimada em 19/5/2008. Considerando-se o início do experimento em 20/10/2007, para as colheitas de sementes aos 8 e aos 14 dias após a antese, os somatórios de graus-dia foram de 1.791,65 e 1.810,25, respectivamente.

Neste trabalho, o comportamento do florescimento contrastou com o relatado por Kumar et al. (2005), que, em Cenchrus ciliaris L., observaram que o aumento na dose de $\mathrm{N}$ atrasou o florescimento. Na literatura não se encontram relatos das fenofases de florescimento e de somatórios de unidades térmicas relacionadas ao florescimento e desenvolvimento de sementes, em capim-mombaça. O somatório de graus-dia após a antese tem sido correlacionado, em forrageiras, com o desenvolvimento de sementes e a época ótima de colheita (Lemke et al., 2003).

Os caracteres massa de perfilho com panícula, densidade de perfilhos com panícula, número de sementes aparentes e puras por panícula e produtividade de sementes aparentes e puras foram afetados pela interação entre dose de $\mathrm{N}$ e época de colheita de sementes (Figura 3). A colheita de sementes aos oito dias após a antese proporcionou os maiores valores de densidade de perfilhos com panículas (23,3 perfilhos $\mathrm{m}^{-2}$, na dose de $231,7 \mathrm{~kg} \mathrm{ha}^{-1}$ de $\mathrm{N}$ ), de sementes aparentes por panícula (375, na dose de $226,2 \mathrm{~kg} \mathrm{ha}^{-1}$ ) e de sementes puras por panícula $\left(125\right.$, na dose de $\left.254,4 \mathrm{~kg} \mathrm{ha}^{-1}\right)$.

A diferença na densidade de perfilhos com panículas em consequência de doses de $\mathrm{N}$ foi baixa. Por ocasião da primeira colheita de sementes, nos pastos sem a aplicação de $\mathrm{N}$, a média de densidade de perfilho com panícula e de número de sementes aparentes e puras por panícula foi reduzida. $\mathrm{Na}$ ausência da adubação nitrogenada, a densidade de perfilhos com panícula
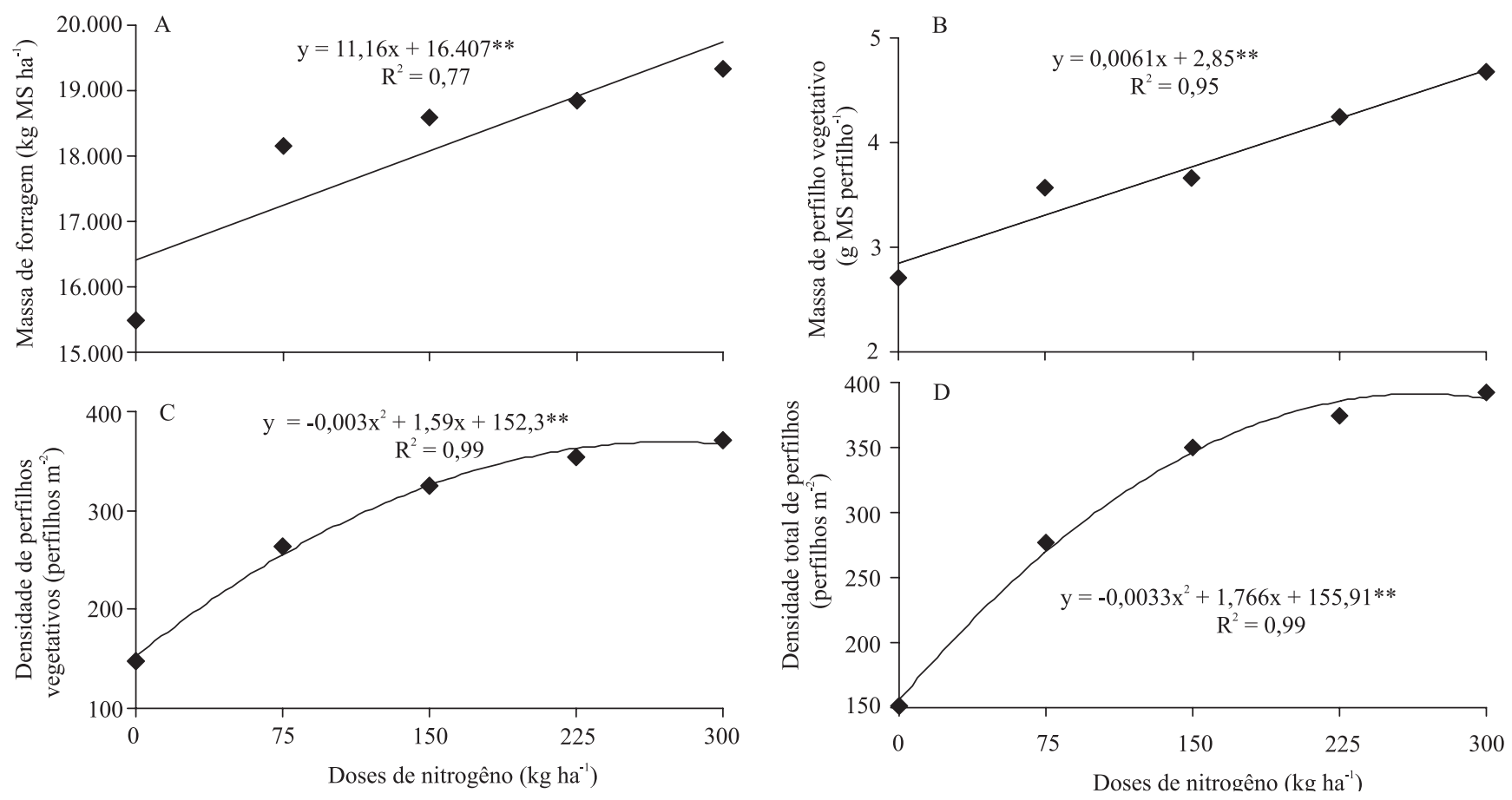

Figura 2. Massa de forragem, massa de perfilho vegetativo, densidade de perfilhos vegetativos e densidade total de perfilhos, em pastos de capim-mombaça, em função de doses de nitrogênio. 
foi baixa também na segunda colheita de sementes. Informações acerca de massa de perfilhos com panícula e de números de sementes aparentes e puras por panícula em $P$. maximum no Brasil não foram encontradas.

Este trabalho confirma os efeitos positivos de adubações de $\mathrm{N}$ relatados em $P$. maximum sobre a densidade de perfilhos com panículas (Condé \& Garcia, 1988; Joaquin et al., 2001). Os baixos números de sementes por panícula, na segunda colheita de sementes, devem ser atribuídos à alta precipitação pluvial $(35 \mathrm{~mm})$ e aos ventos fortes registrados no dia 29 de maio, que causaram queda considerável de sementes das panículas.
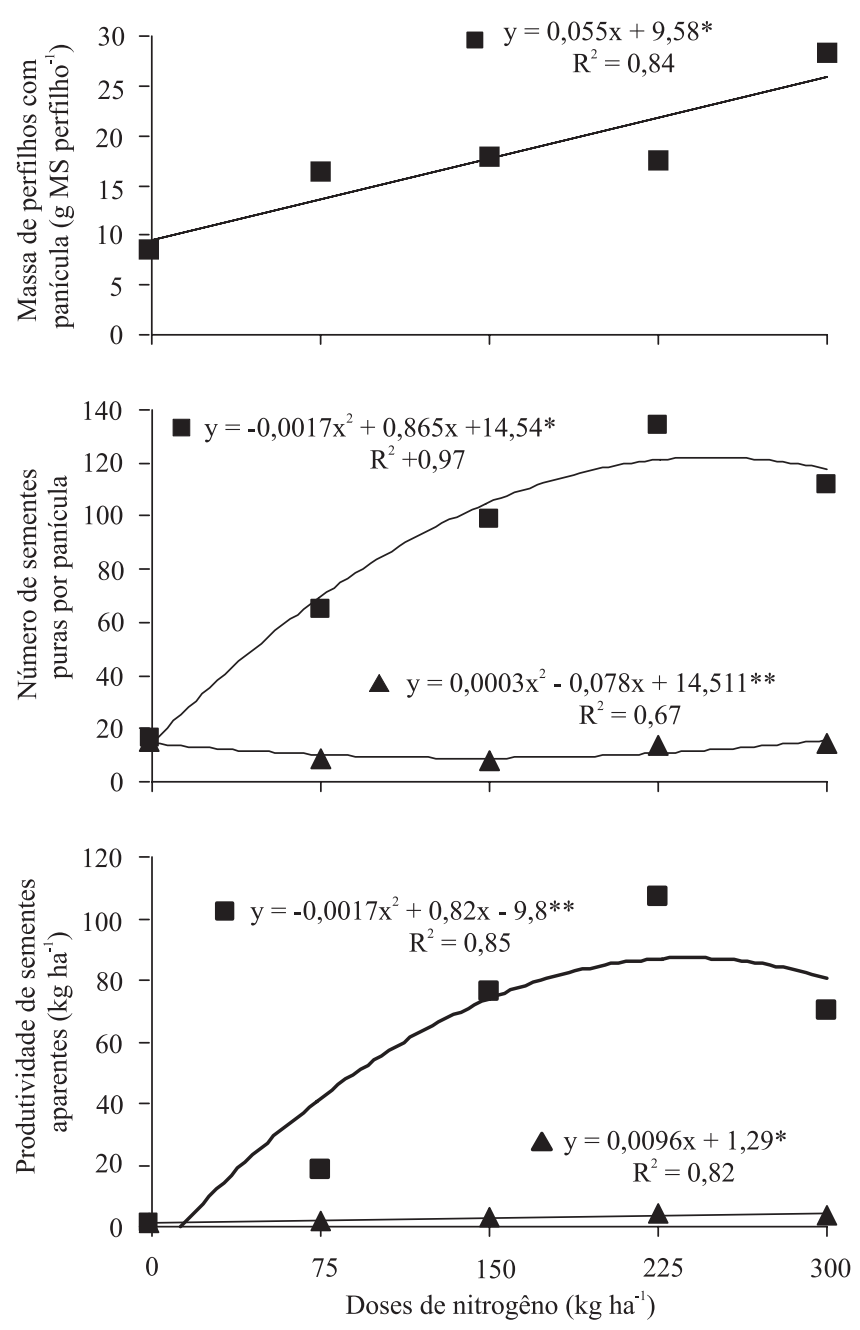

É importante destacar que as máximas produtividades de sementes aparentes e puras, obtidas com as doses de 241,2 e $250,0 \mathrm{~kg} \mathrm{ha}^{-1}$ de $\mathrm{N}$ na primeira colheita de sementes, atingiram 89,1 e $28,2 \mathrm{~kg} \mathrm{ha}^{-1}$, respectivamente. Souza (1999) menciona que a produtividade de sementes com as cultivares de P. maximum são baixas. Hacker (1999) relata produtividades de sementes aparentes de 263 e $467 \mathrm{~kg} \mathrm{ha}^{-1}$, em cultivares de porte baixo, e de 52 e $128 \mathrm{~kg} \mathrm{ha}^{-1}$, em cultivares de porte alto. Joaquin et al. (2001) relata que o aumento na dose de $\mathrm{N}$ elevou a produtividade de sementes e isso, em parte, foi atribuído ao aumento do número de ramificações
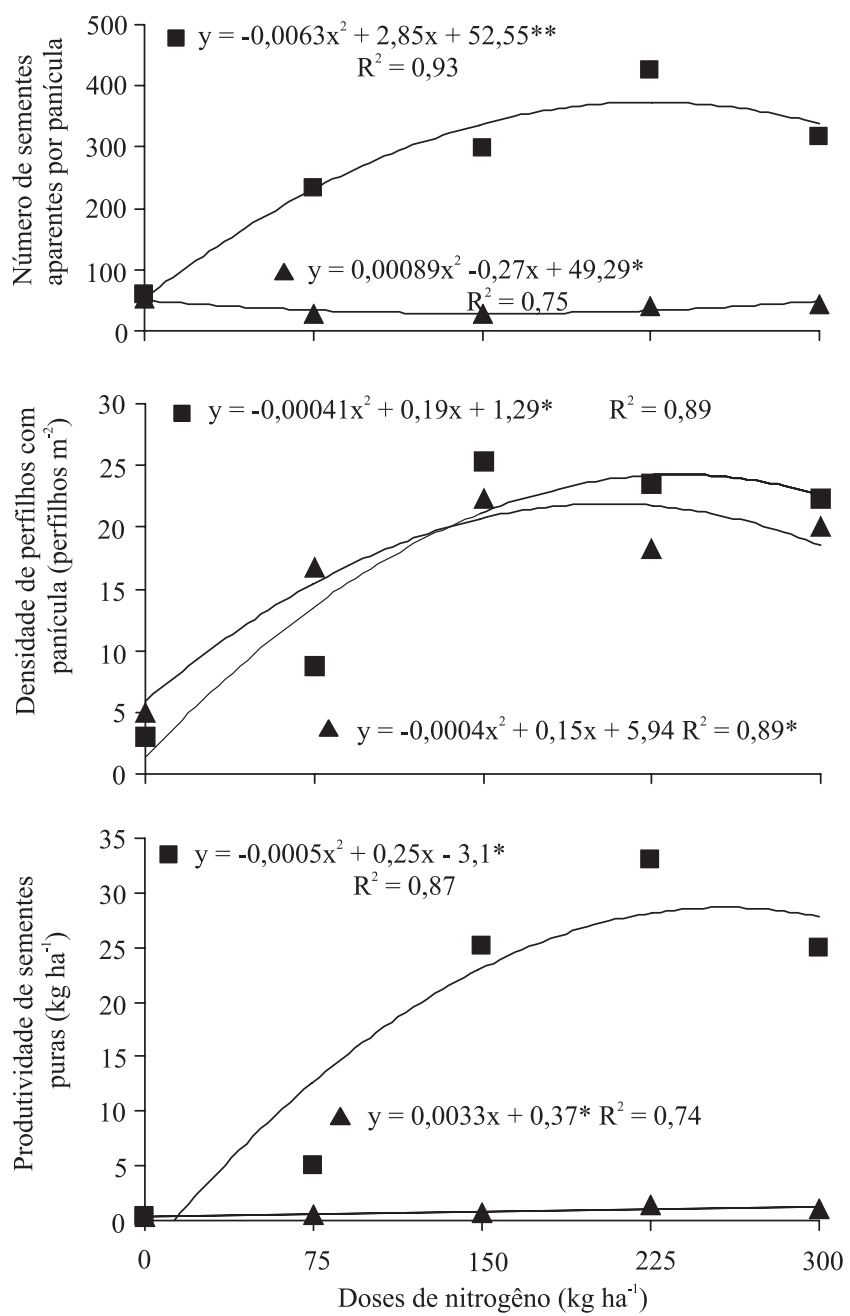

Figura 3. Massa de perfilhos com panícula, densidade de perfilhos com panícula, número de sementes aparentes por panícula, número de sementes puras por panícula, produtividade de sementes aparentes e produtividade de sementes puras, em pastos de capim-mombaça, em função de doses de nitrogênio e épocas de colheita de sementes. 
por panícula e do comprimento de panículas. Nesse estudo, a degrana de sementes com a colheita, aos 6 e 14 dias após a antese, atingiu 13 e 28\%, respectivamente. Matias et al. (1992) relataram que, em Cuba, produtividades de sementes puras por volta de $40 \mathrm{~kg} \mathrm{ha}^{-1}$ podem ser consideradas como adequadas para a produção comercial, em $P$. maximum. No Brasil, não foi localizado nenhum trabalho que avaliasse a produção de forragem combinada com a de sementes em capim-mombaça.

Os caracteres número de sementes aparentes e puras por $\mathrm{m}^{2}$, índice de colheita de sementes aparentes e puras, produtividade de sementes puras viáveis e germinação de sementes foram afetados pela interação entre dose de $\mathrm{N}$ e época de colheita de sementes (Figura 4). No entanto, a percentagem de sementes puras, com média
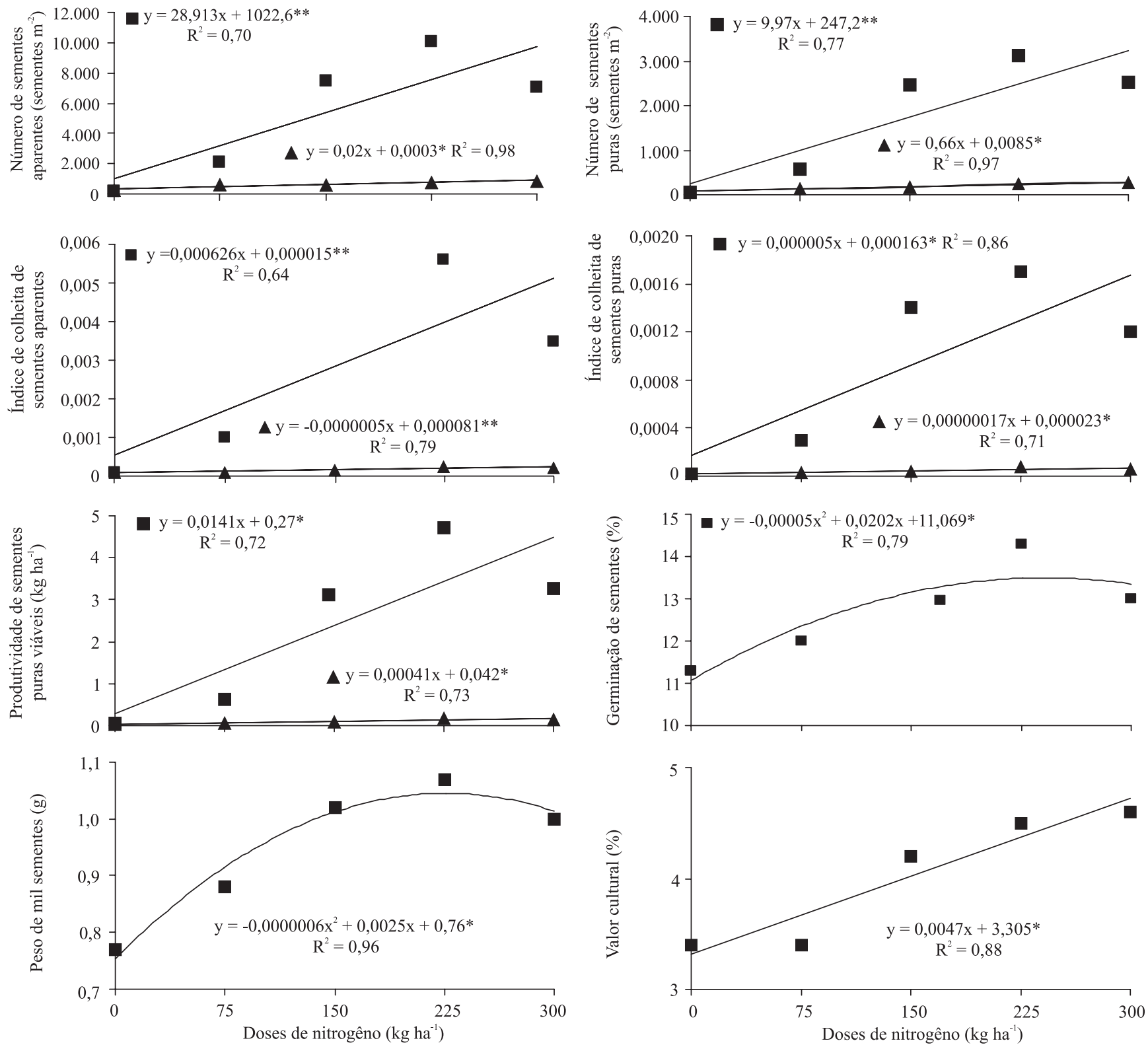

8 Dias

14 Dias

Figura 4. Número de sementes aparentes, número de sementes puras, índice de colheita de sementes aparentes, índice de colheita de sementes puras, produtividade de sementes puras viáveis e germinação de sementes, peso de mil sementes e valor cultural, em pastos de capim-mombaça, em função de doses de nitrogênio e épocas de colheita de sementes. 
geral de $31 \%$, não foi afetada significativamente pelos tratamentos.

As altas massas de forragem foram determinantes para os baixos índices de colheita de sementes observados. Kalton et al. (1996) observaram que características vegetativas, como folhosidade, capacidade de perfilhamento e persistência sob pastejo, em gramíneas temperadas, tendem a reduzir a produção de sementes.

Com relação à produtividade de sementes puras viáveis, somente na colheita aos oito dias após a antese, os valores foram superiores à $3,4 \mathrm{~kg} \mathrm{ha}^{-1}$, nas doses de 225 e $300 \mathrm{~kg} \mathrm{ha}^{-1}$ de N. A baixa proporção de sementes puras deve ser atribuída à variabilidade no desenvolvimento de panículas e à possível alta participação de sementes maturas degranadas das panículas. Além disso, no período de março, que precedeu as colheitas de sementes, a precipitação reduziu-se, o que, em parte, pode ter afetado a produção de sementes. Favoretto \& Rodrigues (1980), não verificaram diferença na proporção de sementes puras colhidas de capim-colonião, aos 28,32 e aos 36 dias após a emergência inicial de panículas.

As taxas de germinação foram baixas (Figura 4). Isto pode ser atribuído aos reduzidos valores de peso de sementes e, possivelmente, à participação de sementes dormentes e imaturas. A percentagem de germinação de sementes foi próxima das obtidas por Zago et al. (1984), que verificaram, em laboratório, germinação de sementes de capim-colonião de 11 e 14\%, nas colheitas de sementes em 11 e 18/5, respectivamente. O efeito do $\mathrm{N}$ sobre a germinação de sementes foi de baixa magnitude. Com relação ao peso de mil sementes e ao valor cultural, a interação entre doses de $\mathrm{N}$ e época de colheita de sementes foi significativa. $\mathrm{O}$ peso de mil sementes contrasta com o relatado por Torres et al. (2009), que verificaram, no capim-tanzânia, média de $1,32 \mathrm{~g}$ ao avaliarem doses de $\mathrm{N}$ entre 0 e $200 \mathrm{~kg} \mathrm{ha}^{-1}$. O baixo valor cultural pode ser atribuído, sobretudo, às baixas taxas de germinação normalmente observadas em sementes colhidas de panículas. As percentagens de sementes puras e de valor cultural foram inferiores às obtidas por Torres et al. (2009) com o capim-tanzânia no México.

Os coeficientes de correlação da produtividade de sementes aparentes, puras e puras viáveis com o número de sementes por panícula, com o peso de mil sementes, e com o número de sementes produzidas por panícula e por unidade de área foram altos (Tabela 2). No entanto, foi baixa a correlação dessas produtividades
Tabela 2. Coeficiente de correlação de Pearson entre componentes de produtividade de sementes com a produtividade $\left(\mathrm{kg} \mathrm{ha}^{-1}\right)$ de sementes aparentes (PSA), puras (PSP) e puras viáveis (PSPV), em pastos de capimmombaça.

\begin{tabular}{|c|c|c|c|}
\hline Caráter & PSA & PSP & PSPV \\
\hline Densidade de perfilhos vegetativos (perfilhos $\mathrm{m}^{-2}$ ) & ns & ns & ns \\
\hline Densidade total de perfilhos (perfilhos $\mathrm{m}^{-2}$ ) & ns & ns & ns \\
\hline Massa de perfilhos com panícula (g MS perfilho-1) & $0,46 * *$ & $0,51 * *$ & $0,52 * *$ \\
\hline Densidade de perfilhos com panículas (perfilhos $\mathrm{m}^{-2}$ ) & $0,57 * *$ & $0,57 * *$ & $0,54 * *$ \\
\hline Densidade total de perfilhos (perfilhos $\mathrm{m}^{-2}$ ) & ns & ns & ns \\
\hline Massa de forragem $\left(\mathrm{kg} \mathrm{MS} \mathrm{ha}^{-1}\right)$ & $0,35^{*}$ & $0,37 *$ & $0,37 *$ \\
\hline Número de sementes aparentes por panícula & $0,93 * *$ & $0,93 * *$ & $0,93 * *$ \\
\hline Sementes puras $(\%)$ & ns & ns & ns \\
\hline Número de sementes puras por panícula (sementes $\mathrm{m}^{-2}$ ) & $0,92 * *$ & $0,94 * *$ & $0,94 * *$ \\
\hline Peso de mil sementes (g) & $0,81 * *$ & $0,81 * *$ & $0,81^{* *}$ \\
\hline Número de sementes aparentes (sementes $\mathrm{m}^{-2}$ ) & $0,99 * *$ & $0,99 * *$ & $0,97 * *$ \\
\hline Número de sementes puras $\left(\right.$ sementes $\left.\mathrm{m}^{-2}\right)$ & $0,97 * *$ & $0,99 * *$ & $0,98 * *$ \\
\hline
\end{tabular}

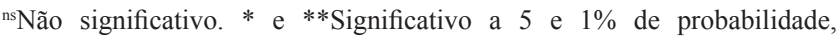
respectivamente.

com a massa de perfilhos com panícula, a densidade de perfilhos com panículas, e a massa de forragem.

\section{Conclusões}

1. A produtividade de colmo, lâmina foliar, material morto e de forragem de capim-mombaça aumenta linearmente com a adubação nitrogenada.

2. A época de colheita é crítica para a eficiência da colheita e para a produtividade de sementes em panículas de capim-mombaça, cujo valor máximo ocorre quando a colheita é realizada oito dias após a antese.

3. Na colheita aos oito dias após a antese, a produtividade de sementes aparentes e puras apresenta resposta quadrática à adubação nitrogenada, com maiores valores obtidos nas doses de 241,2 e $250,0 \mathrm{~kg} \mathrm{ha}^{-1}$ de $\mathrm{N}$, respectivamente.

\section{Referências}

BOONMAN, J.G. East Africa's grasses and fodders: their ecology and husbandry. Dordrecht: Kluwer Academic, 1993. 343p. (Tasks for vegetation science, 29).

BOONMAN, J.G. Experimental studies on seed production of tropical grasses in Kenya. 2. Tillering and heading in seed crops of eight grasses. Netherlands Journal of Agricultural Science, v.19, p.237-249, 1971.

BRAGA, G.J.; MELLO, A.C.L. de; PEDREIRA, C.G.S.; MEDEIROS, H.R. de. Fotossíntese e taxa diária de produção de 
forragem em pastagens de capim-tanzânia sob lotação intermitente. Pesquisa Agropecuária Brasileira, v.44, p.84-91, 2009.

BRASIL. Ministério da Agricultura e Reforma Agrária. Secretaria Nacional de Defesa Agropecuária. Departamento Nacional de Defesa Vegetal. Coordenação de Laboratório Vegetal. Regras para análise de sementes. Brasília: MDA, 1992. 365p.

CANTO, M.W. do; BONA FILHO, A.; MORAES, A. de; HOESCHL, A.R.; GASPARINO, E. Animal production in Tanzania grass swards fertilized with nitrogen. Revista Brasileira de Zootecnia, v.38, p.1176-1182, 2009.

CARNEVALLI, R.A.; SILVA, S.C. da; BUENO, A.A.O.; UEBELE, M.C.; BUENO, F.O.; SILVA, G.N.; MORAES, J.P. Herbage production and grazing losses in Panicum maximum cv. Mombaça under four grazing managements. Tropical Grasslands, v.40, p.165-176, 2006.

CONDÉ, A. dos R.; GARCIA, J. Efeito de níveis e épocas de aplicação de nitrogênio na produção e qualidade das sementes do capim-colonião. Revista Brasileira de Sementes, v.10, p.33-42, 1988.

DIAS, M.C.L. de L.; ALVES, S.J. Avaliação da viabilidade de sementes de Panicum maximum Jacq. pelo teste de tetrazólio. Revista Brasileira de Sementes, v.30, p.152-158, 2008.

EUCLIDES, V.P.B.; COSTA, F.P.; MACEDO, M.C.M.; FLORES, R.; OLIVEIRA, M.P. de. Eficiência biológica e econômica de pasto de capim-tanzânia adubado com nitrogênio no final do verão. Pesquisa Agropecuária Brasileira, v.42, p.1345-1355, 2007.

FAVORETTO, V.; RODRIGUES, L.R.A. Efeito de diferentes épocas de colheita e processos de secagem sobre a viabilidade de sementes de capim-colonião (Panicum maximum Jacq.). Revista Brasileira de Zootecnia, v.9, p.271-230, 1980.

GOBIUS, N.R.; PHAIKAEV, C.; PHOLSEN, P.; RODCHOMPOO, O.; SUSENA, W. Seed yield and its components of Brachiaria decumbens cv. Basilisk, Digitaria milanjiana cv. Jarra and Andropogon gayanus cv. Kent in north-east Thailand under different rates of nitrogen application. Tropical Grasslands, v.35, p.26-33, 2001.

HACKER, J.B. Crop growth and development: grasses. In: LOCH, D.S.; FERGUNSON, J.E. (Ed.). Forage seed production: tropical and subtropical species. Wallingford: CAB International, 1999. v.2, p.41-56.

JANK, L.; MARTUSCELLO, J.A.; EUCLIDES, V.B.P.; VALLE, C.B. do; RESENDE, R.M.S. Panicum maximum. In: FONSECA, D.M. da; MARTUSCELLO, J.A. (Ed.). Plantas forrageiras. Viçosa: UFV, 2010. p.166-196.

JOAQUIN, B.M.; HERNANDEZ, J.; PÉREZ, J.G.; HERRERA, G.; GARCIA, G.; TREJO, C. Fertilización nitrogenada y momento de cosecha em la producción de semilla de pasto guinea (Panicum maximum Jacq.): parámetros y componentes de rendimiento. Pasturas Tropicales, v.23, p.10-15, 2001.

JORNADA, J.B.J.; MEDEIROS, R.B. de; PEDROSO, C.E.S.; SAIBRO, J.C. de; SILVA, M.A. da. Efeito da irrigação, épocas de corte da forragem e doses de nitrogênio sobre o rendimento de sementes de milheto. Revista Brasileira de Sementes, v.27, p.50-58, 2005.

KALTON, R.R.; BARKER, R.E.; WELTY, R.E. Seed production. In: MOSER, L.E.; BUXTON, D.R.; CASLER, M.D. (Ed.). Cool season forage grasses. Madison: American Society of Agronomy, 1996. p.383-411.

KUMAR, D.; DWIVEDI, G.K.; SINGH, S.N. Seed yield and quality of buffel grass (Cenchrus ciliaris) as influenced by row spacing and fertilizer level. Tropical Grasslands, v.39, p.107-111, 2005.

LEMKE, B.M.; GIBSON, L.R.; KNAPP, A.D.; DIXON, P.M.; MOORE, K.J; HINTZ, R. Maximizing seed production in eastern Gamagrass. Agronomy Journal, v.95, p.863-869, 2003.

MATIAS, C.; ESPERANCE, M.; RUZ, V. Potencial de producción de semilla y su germinacion em cruzamientos y selecciones de Panicum maximum Jacq. Pastos y Forrajes, v.15, p.25-32, 1992.

MONTEIRO, J.M.C., FAVORETTO, V.; REIS, R.A. Épocas de rebaixamento e níveis de nitrogênio na produção e qualidade de sementes de capim-colonião. Pesquisa Agropecuária Brasileira, v.19, p.545-552, 1984.

MUIR, J.P.; JANK, L. Guineagrass. In: MOSER, L.E.; BURSON, B.L.; SOLLENBERGER, L.E. (Ed.). Warm-season $\left(\mathbf{C}_{4}\right)$ grasses. Madison: Soil Science Society of America, 2004. p.589-621.

NERY, J.T.; MARTINS, M. de L.O.F.; SANT'ANA, J.L.N. Variabilidade da precipitação no Brasil Meridional. Acta Scientiarum, v.24, p.1687-1695, 2002.

SANGAKKARA, V.R. Relationships between nitrogen fertilizer, defoliation frequency and seed productivity of Panicum maximum Jacq. Seed Research, v.16, p.206-210, 1988.

SANTOS, H.G. dos; JACOMINE, P.K.T.; ANJOS, L.H.C. dos; OLIVEIRA, V.A. de; OLIVEIRA, J.B. de; COELHO, M.R.; LUMBRERAS, J.F.; CUNHA, T.J.F. (Ed.). Sistema brasileiro de classificação de solos. Rio de Janeiro: Embrapa Solos, 2006. 306p.

SAS INSTITUTE. SAS user's guide: statistics. Cary: SAS Institute, 2002. 419p.

SOCIEDADE BRASILEIRA DE CIÊNCIA DO SOLO. Comissão de Fertilidade do Solo - RS/SC. Recomendações de adubação e de calagem para os Estados do Rio Grande do sul e Santa Catarina. 3.ed. Passo Fundo: Sociedade Brasileira de Ciência do Solo, 1995. 223p.

SOUZA, F.H.D. Panicum maximum in Brazil. In: LOCH, D.S.; FERGUNSON, J.E. (Ed.). Forage seed production. 2. Tropical and subtropical species. Wallingford: CAB International, 1999. p.363-370.

TORRES, B.M.J.; CANCINO, S.J.; HERNÁNDEZ-GARAY, A.; PÉREZ, J.P. Efecto de la fertilización nitrogenada sobre el rendimiento y calidad de semilla de pasto guinea. Revista Mexicana de Ciencias Pecuarias, v.47, p.69-78, 2009.

VILlA NOVA, N.A.; TONATO, F.; PEDREIRA, C.G.S.; MEDEIROS, H.R. de. Método alternativo para cálculo da temperatura base de forrageiras. Ciência Rural, v.37, p.545-549, 2007.

ZAGO, C.P.; NASCIMENTO JÚNIOR, D.; ALVARENGA, E.M.; CRUZ, M.E. Produção de sementes de forrageiras. I. Efeito da época de colheita nos capins andropogon (Andropogon gayanus var. bisquamulatus cv. Planaltina), setária (Setaria sphacelata var. Sericea cv. Kazungula) e colonião (Panicum maximum Jacq.). Revista Brasileira de Zootecnia, v.13, p.463-470, 1984.

$\overline{\text { Recebido em } 12 \text { de maio de } 2010 \text { e aprovado em } 11 \text { de outubro de } 2010}$ 